\title{
OCCUPATIONAL AND ENVIRONMENTAL EXPOSURE VERSUS REPRODUCTIVE HEALTH
}

\author{
By \\ Mansour NA \\ Department of Occupational and \\ Environmental Medicine, Faculty of Medicine, Cairo University.
}

\begin{abstract}
Nowadays a special attention is focused on a variety of Occupational and Environmental exposures and their impact on male and female reproductive health. Such exposures may negatively affect the reproductive process causing reduced fertility and adverse pregnancy outcomes in the exposed population.

This article aims at evaluating the impact of Occupational and Environmental exposures to several widespread toxicants on reproductive health by reviewing most recent published literature. The results from the presented studies suggest that there are strong and rather consistent indications that the reproductive system is particularly vulnerable to insult from exposure to widespread occupational and environmental agents. Considering the possible health effects, more epidemiologic data is needed.

Keywords: Occupational exposures, Environmental exposures, Reproductive health, reduced fertility, adverse pregnancy outcomes.
\end{abstract}

Introduction

The presence of hazardous conditions in workplaces has raised concerns about the potential effects of occupational exposure on reproductive health. Occupational exposure among men may result in direct effects on the male reproductive system. Also working women during pregnancy may be exposed to a variety of chemical, physical and psychosocial factors at work. This occupational exposure may directly affect the outcome of pregnancy, such as spontaneous abortion, stillbirth, pre-term birth, small-for-gestational age and birth weight. Occupational exposure may also interact with foetal development, 
resulting in health effects in the offspring that range from congenital birth defects, neurobehavioral disorders at young age and even cancer in older age. Thus, the reproductive system of both women and men can be affected by occupational exposure.

Exposure to reproductive toxins may cause one to become infertile or to have difficulty conceiving a child. Accordingly, reproductive toxins may affect the parent, developing child (even after birth), or both. A reproductive toxicant is an agent that alters male or female fecundity or affects couplespecific factors, resulting in an alteration in fertility (Ulrike et al., 2005).

According to the World Health Organisation as regard new infertility prevalence calculation, one in every four couples in developing countries had been found to be affected by infertility (WHO, 2012).

National Institute for Occupational Safety and Health (NIOSH) postulated that about $10 \%$ to $15 \%$ of couples are unable to conceive a child after 1 year of trying to become pregnant, about 1 in every 6 pregnancies ends in a miscarriage-the unplanned termination of a pregnancy, about $2 \%$ to $3 \%$ of babies are born with a major birth defect, about $7 \%$ of babies born in the United States are born underweight or prematurely and about $10 \%$ of children in the United States have some form of developmental disability (NIOSH, 1999)

Although studies have found that workplace exposures affect the reproductive system; these effects do not necessarily occur in every worker. Whether individuals are affected or not depends on how much of the hazard they are exposed to, how long they are exposed, how they are exposed, and other personal factors.

\section{Physiological consideration}

Luteinising Hormone (LH) and Follicle Stimulating Hormone (FSH) are generally viewed as necessary for normal spermatogenesis. Presumably the effect of LH is secondary in inducing high intratesticular concentrations of testosterone. Therefore, FSH from the pituitary gland and testosterone from the Leydig cells act upon the Sertoli cells within the seminiferous tubule epithelium to initiate spermatogenesis.

The spermatogenic cycle spans 72 days in humans and can be disrupted by toxicants at any stage of cell differentiation, giving rise to reduced 
sperm counts, morphologically abnormal sperm, impaired stability of sperm chromatin or sperm DNA damage (Mangelsdorf et al, 2003). Toxins accumulating in the epididymis, prostate, vesicular seminalis or seminal fluid may impair normal progressive sperm motility. The neuroendocrine control of spermatogenesis can be disrupted by actions on the testis (secretion of androgens from Leydig cells or Inhibin B from Sertoli cells) or the central nervous system (gonadotrophin-releasing hormone released from the hypothalamus or gonadotrophins from the pituitary). Toxins that disrupt the stem cells are likely to cause delayed, long-lasting and possibly permanent effects, while actions on the later stages most likely result in transient effects. Experimental research has established highly specific site of actions of various chemicals.

The precise, finely tuned control of the female reproductive system is accomplished by the anterior pituitary in response to positive and negative feedback signals from the ovaries. The appropriate release of FSH and LH during the ovarian cycle controls normal follicular development. During the preovulatory period of the menstrual cycle, follicle recruitment and development occur under the influence of FSH and LH. The latter stimulates the production of androgens by thecal cells, whereas the former stimulates the aromatization of androgens into oestrogens by the granulosa cells and the production of Inhibin, a protein hormone. Inhibin acts at the anterior pituitary to decrease the release of FSH. This prevents excess stimulation of follicular development and allows continuing development of the dominant follicle-the follicle destined to ovulate. Oestrogen production increases, stimulating both the LH surge (resulting in ovulation) and the cellular and secretory changes in the vagina, cervix, uterus and oviduct that enhance spermatozoa viability and transport (Gracia, 1998).

\section{Hazards identification at the workplace affecting the reproductive health:}

Occupational hazards are the best documented risk factors for impaired reproductive function. These may include physical exposures (radiant heat, ionizing radiation, and high frequency electromagnetic radiation), chemical exposures (some solvents as carbon 
disulfideandethyleneglycolethers, some pesticides as dibromochloropropane, ethylendibromide and DDT/DDE, some heavy metals as inorganic lead and mercury) and work processes such as metal welding beside psychosocial stressors. For other toxicants the evidence is only suggestive and further evaluation is needed before conclusions can be drawn. Whether compounds as phthalates and bisphenol A that are present in a large number of industrial and consumer products entails a risk remains to be established (Bonde , 2010).

We can categorize the outcome of reproductive toxicity due to occupational exposure into male reproductive dysfunction, primarily measured by semen quality and fecundity. The second issue focuses on the female reproductive system and the influence of maternal exposure on fertility and pregnancy outcomes. Beside the impact of maternal exposure on the offspring, which is going to be manifested by birth defects.

Chemical agents in workplace affecting reproductive health and mechanisms of toxicity:

Metals

\section{Male reproductive dysfunction}

Metal production employees are predominantly males, so most studies concern the effects on male spermatogenesis.

There is evidence of an adverse effect of inorganic lead on male reproduction and fecundity. Studies have shown that lead may interfere with the reorganization and tight packaging of sperm DNA during spermatogenesis by competition with zinc- on protaminebinding sites.

Lead is a ubiquitous toxic heavy metal (García et al., 2010). Researches suggest a role for the ubiquitin proteasome system (UPS) in modulating metal-induced toxicity (Yen et al., 2005). The UPS is a highly conserved pathway that plays an important role in the selective degradation of specific cellular proteins (Marx, 2002). The UPS acts through posttranslational modifications of key transcriptional regulators, impacting various cellular events including cell cycle progression, signal transduction, transcriptional regulation, apoptosis, and DNA repair (DiAntonio et al., 2001). Biochemical data indicate that the activity of the UPS is high during spermatogenesis (Rajapurohitam et al., 2002), which 
is most likely related to the high requirement for massive breakdown of cytoplasmatic and nuclear proteins during this process.

Although the biochemical and molecular mechanisms of action of lead remain still unclear, there are some studies that point out indirect mechanisms of genotoxicity such as inhibition of DNA repair or production of free radicals (García et al., 2010).

Cadmium (Cd) exposure was shown to activate ubiquitin-dependent proteolysis pathway in experimental studies (Yu et al., 2008).A study of single dose $\mathrm{Cd}$ chloride treatment in rat found that $\mathrm{Cd}$ significantly reduced serum testosterone $(\mathrm{T})$ level at doses of 0.20 and $0.3 \mathrm{mg} / 100 \mathrm{~g}$ body weight (Sen Gupta et al., 2004).

Wirth and Mijal (2010) reviewed the effects of exposure to low levels of Lead, cadmium, mercury, and arsenic on measures of male fertility (semen quality and reproductive hormone levels) and potentially modifying effects of genetic polymorphisms. They mentioned that the potential modifying effects of genetic polymorphisms has not been fully explored.

\section{Female reproductive dysfunction}

Heavy metals such as lead and mercury (especially among dental assistants working) have been shown to interfere with the endocrine system and this might explain why exposed women present menstrual disorders, delayed conception rates. It was found that neural tube defects are associated with lead exposure. Also, a study in Mexico City found a dose response relationship between the risk of spontaneous abortion and the blood lead level (HerzPicciotto, 2000).

Further, nickel and manganese have been known to be toxic to reproduction for many years. Systematic studies in the last few decades have shown that reproductive effects may be observed at exposure levels which were previously considered safe. These effects include increased risk of spontaneous abortion, developmental toxicity in the offspring, stillbirth and delay in conception (Figà et al, 2001).

\section{Solvents}

\section{Male reproductive dysfunction}

Organic solvents have a wide range of applications in all branches of industry. Workers have often encountered high exposure levels 
because of the high volatility of several organic hydrocarbons.

Glycol ethers [in particular 2-ethoxyethanol (2-EE) and 2-methoxyethanol (2-ME)] are an important group of organic solvents widely used. Cherry et al. (2008) studied glycol ethers exposure and male infertility. They concluded that Glycol ether exposure was related to low motile sperm count in men attending fertility clinics. This suggests that glycol ethers continued to be a hazard for male fertility

Trichloroethylene (TCE) and tetrachloroethylene (PER) are used as degreasers. PER has been widely used in the dry-cleaning industry and has been found to affect reproduction of male and female workers (Tina et al, 2006).

Trinitrotoluene (TNT) induces reproductive toxicity through oxidative DNA damage mediated by its metabolite (DNA damage was enhanced by NADH, suggesting that NADH-mediated redox reactions involving TNT metabolites enhanced toxicity). This oxidative DNA damage in the testis plays a role in reproductive toxicity induced by TNT and other nitro aromatic compounds (Shino et al, 2002).

\section{Female reproductive dysfunction}

Exposure to solvents continues to be an important contributor to female reproductive toxicity.

Many solvents have negative effects on the menstrual cycle and pregnancy outcome include carbon disulfide (through interference with hormonal equilibrium), styrene, trichloroethylene and tetrachloroethylene(dry cleaners), glycol ethers and aromatic hydrocarbons especially toluene and benzene.

Working with petrochemicals is known to increase the risk of cytogenetic alterations and mutagenic effects, in both somatic cells and in embryonic tissues. Many studies of adverse reproductive outcomes (spontaneous abortions, congenital defects and childhood cancers) among workers exposed to organic solvents have been conducted. Further, it was found that maternal exposure to organic solvents was associated with reduced birth weight (Ha et al., 2002).

\section{Other chemical Hazards}

\section{Endocrinal disruptors}

Endocrinal disruptors are example of chemical agents with negative impact on the reproductive system. These disruptors include dioxin, bisphenol A, 
phthalates,DDTas well as environmental contaminants present in industrial waste (e.g. polychlorinated biphenyls (PCB)). They mimic natural hormones, inhibit the action of hormones, or alter the normal regulatory function of the endocrine system and have potential hazardous effects on male reproductive axis causing infertility. Testicular and prostate cancers, abnormal sexual development, undescended testis, chronic inflammation, Sertoli-cell-only pattern, hypospadias, altered pituitary and thyroid gland functions are also observed (Suresh and Run, 2008).

Endocrine disruption of spermatogenesis may be represented by four mechanisms, including (1) epigenetic changes to the genom e.g. methylation status of genomic DNA. (2) apoptosis of germ cells, (elevation of pro-apoptotic molecules, including Fas-L, caspase- 3 and caspase- 6 Bax, $\mathrm{Bak}$, and Bid, and a decrease in antiapoptotic molecules $\mathrm{Bcl} 2$ and $\mathrm{Bclw}$ (Bozec et al., 2004) (3) dysregulation of androgenic signaling (Testicular androgenic signaling may be impaired via several mechanisms, including decreased Leydig cell population, impaired Leydig cell steroidogenesis, and dysregulation of the HPT axis), and (4) disruption of Sertoli and other spermatogenesis support cells( Sertoli cell number is directly representative of the spermatogenic potential of the testis) (Mauduit et al., 2006).

Additionally, Patisaul (2013) reported that endocrinal disruptors may also act in the brain by stimulating hypothalamic neurons, thereby releasing kisspeptin and promoting the maturation of the hypothalamus, causing earlier onset of puberty, or even precocious puberty.

Bisphenol-A (BPA): is an example of an industrial estrogen-like chemical that has a weak estrogenic activity. It is used in the manufacture of epoxy, polycarbonate and corrosion-resistant polyester-styrene resins required for food packaging materials in industrial processing. BPA have been shown to leach from plastic used in food processing and wrapping (NIOSH, 1985), from lacquer coating in food cans ranging from 0 to $33 \mu \mathrm{g}$ per can. BPA is also used as a dental sealant and has been reported to be found in the saliva of patients having dental sealants (Fung et al., 2000).

BPA has been shown to act as a meiosis-disrupting agent by selectively interfering with centrosome and 
microtubule organization (possibly by a mechanism that degrades centrosomal proteins and thus perturbs the spindle microtubule organization and chromosome segregation). This moderate activity of BPA, unlike other potent estrogenic agents that depolymerize microtubules, seems to be due to centrosome disorganization and fragmentation resulting in poorly organized spindles in both meiotic and mitotic systems (Can et al, 2005).

Phthalate Esters: are abundant industrial chemicals used in the production of plastics and are present in many personal care products including cosmetics to intensify chemical fragrances in them. Phthalate monoesters target Sertoli cell functions in supporting the spermatogenesis process. This may be due to the effect of phthalates in reducing the ability of Sertoli cells to respond to FSH (Hauser et al., 2005).

Many chemicals, including phthalates, are conjugated with glucuronic acid, rendering them more water soluble, thereby facilitating their excretion. It was hypothesized that PCB metabolites inhibit the glucuronidation of phthalate monoesters resulting in potentiating its effect (Hauser et al., 2005)
In the fetal testis, in utero exposure to Di (n-butyl) phthalate (DBP) reportedly resulted in reduced testosterone levels, Leydig cell aggregates, and multinucleated gonocytes (MNG). Sertoli cells in DBP-exposed fetal testis had morphological changes. The effect of DBP on Sertoli cell morphology at the level of light microscopy was reversed after birth and cessation of exposure. This data indicate that fetal Sertoli cells are targeted by exposure in utero to DBP (Kleymenova et al, 2005)

Further, Sharpe (2006) reported that reduction of testicular androgens during fetal development is likely to decreases Sertoli cell number and hence, decrease the spermatogenic potential of the testis.

DDT and polychlorinated biphenyls (PCBs) : A recent Brazilian study quantified organochlorine compounds in infertile women and compared them to a control group of fertile women. Exposure to organochlorine compounds was most prevalent in infertile women, confirming the data from literature, indicating that these compounds may negatively affect female fertility (Bastos et al., 2013).

Toft et al. (2005) mentioned that persistent organochlorine pollutants including polychlorinated biphenyls 
interfere with sperm motility and sperm DNA integrity at exposure levels that are encountered in populations with high body burdens related to marine diet and environmental contamination.

Dioxins (TCDD): Warren et al (2010) found that no credible evidence to support the conclusion that TCDD adversely affects spermatogenesis, with the exception of a small number of male rats in which testicular and epididymal lesions have been described. Ohsako et al (2001) alternatively suggested that the effects of TCDD on androgen signaling, reproductive organ weights and sperm transit through the epididymides are more logic potential explanations for the reported decrease in epididymal sperm counts.

\section{Dysregulation of androgen} signaling and TCDD: TCDD treatment induced a decrease in androgen receptor (AR) gene expression in ventral prostate and decreased weight, both evidence of decreased androgen signaling (Ohsako et al., 2001). Morrow et al. (2004) reported that activation of the AhR in prostate cells by TCDD could inhibit androgen-dependent proliferation, which was mediated by cross-talk between the AhR and the AR. Competition between the AR and the
AhR for nuclear transcription factors is another possibility.

\section{Dysregulation of epididymal} function and TCDD: Warren et al (2010) postulated that the adverse effects of TCDD including decrease in epididymal or sperm counts (to the extent that sperm counts decreased by almost 40\%) without effect on testes are mediated via changes in epididymal function. In general, phagocytosis of spermatozoa by the epithelial cells of the cauda epididymidis is very low. It has previously been suggested that damaged spermatozoal cells can be phagocytosed. A second possibility is that the blood-epididymal barrier is compromised, resulting in activation of the immune system, thus allowing macrophages to readily enter the lumen of the epididymis and attack maturing spermatozoa (Cyr et al., 2007).

\section{Polycyclic aromatic hydrocarbons} (PAH): Pru et al. (2009) mentioned that activation of the aryl hydrocarbon receptor (AHR) by polycyclic aromatic hydrocarbons (PAH), a ubiquitous class of environmental and occupational biohazards, accelerates germ cell depletion in female mice during prenatal and postnatal life. Like AHR, BAX is also functionally 
required for PAH to kill oocytes. They showed that PAH upregulates ovarian expression of not just Bax but a large cassette of proapoptotic genes that function at multiple steps of the cell death signaling pathway. They further showed that ovarian expression of p53 and several proapoptotic genes that are known transcriptional targets of p53 are increased by PAH treatment, and that mice lacking functional p53 are resistant to the ovotoxic effects of in vivo $\mathrm{PAH}$ exposure. They finally added that this study provided further mechanistic insights into how $\mathrm{PAH}$ accelerate oocyte depletion in females and adds p53 to the list of genes whose functional importance to $\mathrm{PAH}$-induced ovotoxicity has been demonstrated by gene knockout technology.

Physical agents in workplace affecting reproductive health:

\section{Radiation}

\section{Male reproductive dysfunction}

Radiation and other agents can cause germ-cell mutations in animal systems. The ultimate fate of the irradiated cell is not only a function of the radiation dose but also influenced by the cell's natural defences, including the ability to detect the DNA lesions and to repair them with high fidelity. Furthermore, recent advances have revealed DNA is not the only cellular target that influences the radiation response. It also interacts directly with lipid and protein signalling pathways and modulates gene expression through a variety of mechanisms including the direct activation of transcription factors. Ionizing radiation-induced activation of these signalling pathways can affect critical processes such as cell cycle regulation, DNA repair, apoptosis and tissue repopulation.

Mobile phones as a source of non ionizing radiation might adversely affect the quality of semen by decreasing mostly motility and also the sperm counts, viability and morphology (Jurewicz et al, 2009). Accordingly, the effects of exposure to electromagnetic waves reinforce the hypothesis of the importance of lifestyle-related factors.

\section{Female reproductive dysfunction}

It is widely accepted that women should avoid all exposures to ionizing radiation in the periconceptional period.

De Santis et al (2005) mentioned that maternal thyroid exposure to diagnostic radiation has been associated with a slight reduction in the birth 
weight. Inadvertent exposure from diagnostic procedures in pregnancy doesn't usually increase the natural risk of congenital anomalies but creates a considerable state of maternal anxiety.

In the last few years the debate on possible health risks of electromagnetic fields has focused on specific sources, namely power lines and, more recently, base stations for cellular telephones. This has drastically diverted the attention of the research and prevention community towards residential exposures. On the other hand, the increasing number of technological process exploiting or generating electromagnetic fields requires greater attention to exposures at the workplace (Vecchia, 1997).

A large number of studies have been undertaken in recent years in an attempt to define the role of domestic exposures. Pasquali et al. (2011) reported that dietary products were associated with the development of poly cystic ovary in susceptible females. Such products include advanced glycated end-products (AGEs). AGEs are reactive derivatives of non-enzymatic glucose-protein reactions. They are endogenously produced by aging, hyperglycemia, and oxidative stress, or exogenously ingested mainly from high-temperature processed, protein-rich foods (e.g. using microwaves ovens).

In the occupational setting, effects of non-ionizing radiation on the reproductive health of women workers have been studied mainly in two areas: the health care sector and in connection with the use of Video Display Terminals (VDTs).

Health professionals using diagnostic and therapeutic devices (e.g. magnetic resonance operators and physiotherapists) are potentially exposed to non-ionizing radiation through the use of ultrasound, microwaves, magnetic resonance and other electrical apparatus. The evidence concerning spontaneous abortion, in occupational settings with heavy use of VDTs, has been reviewed by Shaw (2001).

\section{Heat and sedentary body posture}

In the occupational setting, a few cross-sectional studies among foundry workers, welders, ceramics workers and bakers have indicated reduced sperm counts in exposed men. It is now well documented that the sedentary work position is associated with an increased scrotal temperature. Men sitting at work for $8 \mathrm{~h}$ a day have an average $0.7^{\circ} \mathrm{C}$ 
increased scrotal temperature during the day in comparison with employees with $<8 \mathrm{~h}$ in the sedentary body position (Hjollund et al,2002).

\section{Psychosocial work stress}

Stress is known to interfere with the endocrine system of women, often manifested by menstrual disorders. Exposure to stressful work conditions and its effects on the reproductive health of women are studied. The main outcomes include: menstrual and fecundity affection also spontaneous abortion in certain occupations such as nurses, manufacturing workers and professional women.

Stress also may lead to chronic anovulation and amenorrhea. This is generally thought to be caused by a decrease in the activity of the hypothalamic GnRH pulse generator with subsequent inhibition of the pituitary-gonadal axis. There is considerable evidence that stressinduced activation of the hypothalamicpituitary-adrenal (HPA) axis plays an important role in suppressing the hypothalamic-pituitary-gonadal (HPG) axis. In animals, Corticotropinreleasing factor (CRF) has been shown to suppress the GnRH pulse generator, resulting in a decrease in pulsatile $\mathrm{LH}$ release. An acute stress during the follicular phase of the menstrual cycle might lead to a premature LH surge and thereby interfere with follicular maturation and ovulation (Jardena et al., 2000).

\section{Measures to be taken to ensure the reproductive health:}

Recognition of the impact of reproductive toxins will provide insight into the necessary precautions to be taken for the protection of reproductive health of both women and men.

Occupational hazards should be considered to warrant protection of women and men trying to conceive. In general, the precautions to be taken for the protection of the reproductive health of both women and men will not differ from the safeguarding of all workers. Improved working conditions in affluent countries have dramatically decreased known hazardous workplace exposures, but millions of workers in less affluent countries are at risk from reproductive toxicants (Bonde , 2010).

Primary control of hazards to levels safe for men and non pregnant and pregnant women is crucial. Engineering controls in addition to personal protective equipment and 
administrative controls are essential (Stijkel and van Dijk, 1995). The adherence to strict standards, which are safe for reproduction and development, is the cornerstone of an effective plan.

\section{References}

1. Bastos AM, de Souza Mdo C, de Almeida Filho GL, Krauss TM, Pavesi T, da Silva LE. (2013) : Organochlorine compound levels in fertile and infertile women from Rio de Janeiro, Brazil. Arq Bras Endocrinol Metabol; 57(5):346-53.

2. Bonde JP, Joffe M, Apostoli P, et al. (2002) : Sperm count and chromatin structure in men exposed to inorganic lead: lowest adverse effect levels. Occup Environ Med; 59:234-242.

3. Bozec A , Chuzel F, Chater S, Paulin C , Bars R , Benahmed M and Mauduit C (2004) : The mitochondrial-dependent pathway is chronically affected in testicular germ cell death in adult rats exposed in utero to anti-androgens. J. Endocrinol; 183: 79-90.

4. Can OS and Cinar O (2005): Bisphenol-A induces cell cycle delay and alters centrosome and spindle microtubular organization in oocytes during meiosis Molecular Human Reproduction; 11(6):389-396.

5. Cherry N1, Moore H, McNamee R, Pacey A, Burgess G, Clyma JA, Dippnall M, Baillie H (2008) : Occupation and male infertility: glycol ethers and other exposures. Occup Environ Med; 65(10):708-14.

6. Cyr DG, Gregory M, Dufresnes J, Dube E, Chan PTK, Hermo L (2007) : The orchestration of occludin, claudins, catenins and cadherins as players involved in maintenance of the bloodepididymal barrier in animals and humans. Asian J Androl; 9:463-475.

7. De Santis M, Di Gianantonio E, Straface G, Cavaliere AF, Caruso A, Schiavon F, Berletti
R, Clementi M (2005) : Ionizing radiations in pregnancy and teratogenesis: a review of literature. Reprod toxicol; 20(3):323-9.

8. DiAntonio A, Haghighi AP, Portman SL, Lee JD, Amaranto AM, Goodman CS (2001): Ubiquitination-dependent mechanisms regulate synaptic growth and function. Nature; 412:449-452.

9. Figà-Talamanca I, Traina E, Urbani E (2001) :Occupational exposure to chemicals: recent evidence on male reproductive effects and biological markers. Occup Med; 51:174-188.

10. Fung EY, Ewoldsen NO, St. Germain HA Jr, Marx DB, Miaw CL, Siew C, Chou HN, Gruninger SE and Meyer DM (2000) :Pharmacokinetics of bisphenol A released from a dental sealant. J Am Dent Assoc; 131, 51-58.

11. Gracia KL (1998): Reproductive System in Encyclopaedia of Occupational Health and Safety

12. García-Lestón J, Méndez J, Pásaro E, Laffon B (2010): Genotoxic effects of lead: an updated review. Environ Int; 36(6):623-36.

13. Ha E, Cho SI, Chen D, et al. (2002): Parental exposure to organic solvents and reduced birth weight. Arch Environ Health; 57:207-214.

14. Herz-Picciotto I (2000): The evidence that lead increases the risk of spontaneous abortion. Am J Ind Med; 38:300-309.

15. Hjollund NH, Storgaard L, Ernst E, Bonde JP, Olsen J (2002) :The relation between daily activities and scrotal temperature. Reprod Toxicol; 16:209-214.

16. Hauser R, Williams $\mathrm{P}$, Altshul L and Calafat A (2005): Evidence of interaction between polychlorinated biphenyls and phthalates in relation to human sperm motility. Environ. Health Perspect; $113: 425-430$.

17. Jardena JP, Pamela UF, Robin SG, Michel F and Sharon LW (2000) :Stimulatory Effects of Stress on Gonadotropin Secretion in EstrogenTreated Women The Journal of Clinical Endocrinology \& Metabolism;85(6):2184-2188 
18. Jurewicz J, Hanke W, Radwan M and Bonde JP (2009): Environmental factors and semen quality. Int $\mathrm{J}$ Occup Med Environ health; 22(4):305-29.

19. Kleymenova E, Swanson C, Boekelheide K and Gaido KW (2005): Exposure in utero to di(nbutyl) phthalate alters the vimentin cytoskeleton of fetal rat Sertoli cells and disrupts Sertoli cellgonocyte contact. Biol Reprod ; 73(3):482-90.

20. Mangelsdorf I, Buschmann J and Orthen B (2003): Some aspects relating to the evaluation of the effects of chemicals on male fertility. Regul Toxicol Pharmacol; 37:356-369.

21. Mauduit C, Florin A , Amara S, Bozec A, Siddeek B et al (2006): Long-term effects of environmental endocrine disruptors on male fertility (French). Gynecol. Obstet. Fertil; 34: 978-984

22. Marx J. (2002): Cell biology. Ubiquitin lives up to its name. Science ;297:1792-1794.

23. Morrow D, Qin C, Smith R and Safe S (2004): Aryl hydrocarbon receptor inhibition of $\mathrm{LNCaP}$ prostate cancer cell growth and hormoneinduced transactivation. J Steroid Biochem Mol Bio; 88:27-36.

24. NIOSH (1985): 4.4'-Isopropylidenedipphenol. Registry of Toxic Effects of Chemical Substances; 4, 3263.

25. Pazquali R, Stener-Victorin E, Yildiz BO, Duleba AJ, Hoeger K, Mason H, et al. (2011) : PCOS Forum: research in polycystic ovary syndrome today and tomorrow. Clin Endocrinol (Oxf); 74:424-33.

26. Patisaul HB (2013): Effects of environmental endocrine disruptors and phytoestrogens on the kisspeptin system. Adv Exp Med Biol; 784:455-79.

27. Pru JK, Kaneko-Tarui T, Jurisicova A, Kashiwagi A, Selesniemi K, Tilly JL(2009): Induction of proapoptotic gene expression and recruitment of p53 herald ovarian follicle loss caused by polycyclic aromatic hydrocarbons. Reprod Sci; 16(4):347-56.
28. Rajapurohitam V, Bedard $\mathrm{N}$ and Wing SS (2002): Control of ubiquitination of proteins in rat tissues by ubiquitin conjugating enzymes and isopeptidases. Am. J. Physiol. Endocrinol. Metab; 282: E739-E745.

29. Sen Gupta R, Kim J, Gomes C, Oh S, Park J, Im WB, Seong JY, Ahn RS, Kwon HB, Soh J(2004) : Effect of ascorbic acid supplementation on testicular steroidogenesis and germ cell death in cadmium-treated male rats. Mol. Cell. Endocrinol ; 221:57-66.

30. Sharpe RM (2006): Pathways of endocrine disruption during male sexual differentiation and masculinisation. Best Pract. Res. Clin. Endocrinol. Metab; 20:91-110.

31. Shaw GM (2001): Adverse human reproductive outcomes and electromagnetic field: a brief summary of the epidemiologic literature. Bioelectromagnetics; 5:S5-S18.

32. Shino HT, Yusuke H, Yasuhiro O, Shinji O, et al (2002): 2,4,6-Trinitrotoluene-induced Reproductive Toxicity via Oxidative DNA Damage by its Metabolite Informa; 36(5): 555 - 566

33. Stijkel A, van Dijk FJ (1995): Developments in reproductive risk management. Occup Environ Med; 52:294-303.

34. Suresh CS and Run W (2008): Endocrine disruptors and estrogenic effects on male reproductive axis. Asian Journal of Andrology; 10(1):134-145.

35. Toft G, Axmon A, Giwercman A, et al. (2005): Fertility in four regions spanning large contrasts in serum levels of widespread persistent organochlorines: a cross-sectional study. Environ Health; 4:26.

36. Toft G1, Axmon A, Lindh $\mathrm{CH}$, Giwercman A and Bonde JP (2008): Menstrual cycle characteristics in European and Inuit women exposed to persistent organochlorine pollutants. Hum Reprod; 23(1):193-200. 
37. Tomei G1, Ciarrocca M, Fiore P, Rosati MV, Pimpinella B, Anzani MF, Giubilati R, Cangemi C, Tomao E and Tomei F. (2008): Exposure to urban stressor and effects on free testosterone in female workers. Sci Total Environ; 25;392(23):198

38. Ulrike L, Mark R, Donald R (2005): Disorders of Reproduction and Development in Clinical Occupational and Environmental Medicine. Elsevier Inc; 618-623.

39. Vecchia P (1997): The health risks of exposure to electromagnetic fields in work environments. Med Lav; 88(6):462-74

40. Vlajković S1, Cukuranović R, Bjelaković MD and Stefanović V (2012): Possible therapeutic use of spermatogonial stem cells in the treatment of male infertility: a brief overview. Scientific World Journal; 37:4151

41. Warren GF, Serena Maharaj B and Daniel G 2010): Dioxin-Induced Changes in Epididymal Sperm Count and Spermatogenesis. Environ Health Perspect; 118(4): 458-464.
42. WHO ( 2012) : National, regional, and global trends in infertility prevalence since 1990: A systematic analysis of 277 health surveys, 12 pages

43. Wirth JJ and Mijal RS (2010): Adverse effects of low level heavy metal exposure on male reproductive function. Syst Biol Reprod Med; 56(2):147-67.

44. Woods DC and Tilly JL (2012): The next (re) generation of ovarian biology and fertility in women: is current science tomorrow's practice? Fertil Steril 98(1):3-10.

45. Yen JL, Su NY, Kaiser P (2005): The yeast ubiquitin ligase SCFMet30 regulates heavy metal response. Mol. Biol. Cell; 16:1872-1882. 